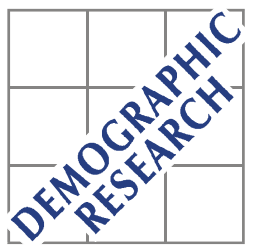

Demographic Research a free, expedited, online journal of peer-reviewed research and commentary in the population sciences published by the Max Planck Institute for Demographic Research Konrad-Zuse Str. 1, D-18057 Rostock · GERMANY www.demographic-research.org

DEMOGRAPHIC RESEARCH

VOLUME 25, ARTICLE 9, PAGES 311-336

PUBLISHED 29 JULY 2011

http://www.demographic-research.org/Volumes/Vol25/9/

DOI: $10.4054 /$ DemRes.2011.25.9

Research Article

\title{
Economic resources and the first child in Italy: A focus on income and job stability
}

\section{Elisabetta Santarelli}

\section{(C) 2011 Elisabetta Santarelli.}

This open-access work is published under the terms of the Creative Commons Attribution NonCommercial License 2.0 Germany, which permits use, reproduction \& distribution in any medium for non-commercial purposes, provided the original author(s) and source are given credit.

See http:// creativecommons.org/licenses/by-nc/2.0/de/ 


\section{Table of Contents}

$\begin{array}{lll}1 & \text { Introduction } & 312\end{array}$

2 Economic resources and childbearing: Theoretical background 314

3 The economic situation of young people in Italy: An overview 317

4 Data, methods, and research hypotheses 319

$\begin{array}{lll}5 & \text { Results } & 324\end{array}$

$\begin{array}{lll}6 & \text { Conclusions } & 327\end{array}$

$7 \quad$ Acknowledgments 329

References 330

$\begin{array}{ll}\text { Appendix } & 335\end{array}$ 


\title{
Economic resources and the first child in Italy: A focus on income and job stability
}

\author{
Elisabetta Santarelli ${ }^{1}$
}

\begin{abstract}
At the turn of the twentieth century Italy registered a lowest-low fertility level, i.e., a total fertility rate of 1.26 children per woman in 2000. In this paper we investigate whether and how in that period economic resources and, in particular, income and job stability were linked with couples' decisions to enter parenthood. With this aim, we use data from ECHP and carry out a longitudinal analysis on a sample of childless married couples to study the transition to their first child. Results show that the couples' employment arrangement played some role in first child rates, with the single earner arrangement experiencing the highest first birth rates. We also find that employed women with labour income have much lower first birth rates than non-working women, while no evidence is found for male earnings and other sources of income. As concerns job instability, we find evidence that it was not significantly linked with the transition to first time parenthood during the investigated period.
\end{abstract}

\footnotetext{
${ }^{1}$ Dr. in Demography. E-mail: esantarelli@inwind.it.
} 


\section{Introduction}

At the end of the twentieth century Italy was characterized by important economic and demographic changes. Firstly, a large increase of educational attainment was observed. In 1995 the proportion of the population aged 25 to 64 that had completed at least upper secondary education was $27 \%$, while in 2002 it was 34\% (OECD 2004a). Young women in particular were the protagonists in this increased school attendance. In the meantime great labour market shifts were taking place. Women were significantly increasing their presence in the labour force, mainly due to the tertiarization of the Italian economy: female employment increased by $10.9 \%$ between 1995 and 2000 (Istat 2000), so that the male breadwinner model was more and more challenged by the dual earner model. During this period part time jobs were increasing, especially among women: female part-time jobs ${ }^{2}$ went from $18.4 \%$ in 1990 to $23.7 \%$ in 2001 (OECD 2004b). However, part-time jobs in Italy were, and still are, rare in comparison with other European countries, and mostly characterized by short-term contracts and high precariousness. Moreover, working hours for part-timers were among the highest in Europe, while full-time working hours were the lowest.

Since the turn of the century, the Italian labour market has become more flexible, because of part time jobs. On the other hand, increasing temporary and other fixed-term contracts have made it more precarious. The share of temporary employment ${ }^{3}$ was $5 \%$ in 1990 and had doubled by 2000 (OECD 2002). The amount of temporary employment had increased since the early 1980s, when Italian governments introduced reforms to give greater flexibility to the labour market, making it easier to create temporary jobs, with a marked intensification of such efforts from the late 1990s. Fixed-term contracts and the use of temporary work agencies were liberalized, and these political reforms hit mainly young people and in particular women, because temporary jobs raised the incidence of transitions from unemployment to limited-duration jobs.

In this context of transformations demographic behaviours have also changed. The prolonged investment in education and the long search for a stable job delay the family formation phases for young people. They are increasingly postponing leaving the parental home, an event that is closely associated with first union and is mostly coincident with marriage (Billari and Ongaro 1998).

At the end of the last century women's increasing presence in the labour market reshaped the gender relationship within couples and increased difficulties in reconciling work and family, with consequences for reproductive choices. At the beginning of the $21^{\text {st }}$ century age at first marriage was very high: in 2001 it was 27.2 years for women

\footnotetext{
${ }^{2}$ Percentages are computed as part-time employment on the total employment. Part-time employment refers to persons who usually work less than 30 hours per week in their main job.

${ }^{3}$ Percentage of dependent employees in temporary jobs.
} 
and 30.2 years for men. At the same time postponement of parenthood caused a rise of female mean age at the birth of the first child. This was 30 years in 2001, among the highest in Europe (Istat 2009a). Childbearing postponement is one of the elements causing the lowest-low fertility, which has been stable below the replacement level since the end of the 1970s (Billari 2005). Total Fertility Rate (TFR) has shown a slight increase since the middle 1990s - it was 1.19 in 1995 and 1.25 in 2001 (Istat 2009a) due to the higher fertility of immigrant couples and a recovery among the youngest generations and more educated women.

In this work we analyze the process leading to parenthood in Italy, and its interrelations with economic resources at the end of the twentieth century, focusing in particular on income and job stability. The link between economic resources and fertility is complex, since it embraces several key dimensions of the lives of individuals and societies (Baizan 2007). Although there have been many studies on the relation between female labour market participation and fertility in Italy (see, e.g., Del Boca 2002; Ongaro and Salvini 2003; Vignoli and Salvini 2008; Salvini, Pasqual, and Vignoli 2009), to date there has been little investigation of the association of fertility with income (see, e.g., Giraldo, Mazzuco, and Michielin 2004; Rondinelli, Aassve, and Billari 2010; Santarelli 2010) and with job stability (Bernardi and Nazio 2001; Salvini and Ferro 2007). This is mostly due to a lack of suitable data for empirical analyses. In fact most demographic surveys in Italy have been weak on economic variables: in particular, information on income is typically missing. Proxies such as educational level or labour participation have been used, with the problem of confounding cultural and economic effects.

Furthermore, dynamic studies at the micro level on the association between parenthood and economic resources in Italy are scarce, because of the lack of data. For this, panel data with a long time dimension or retrospective surveys with complete employment and fertility histories are needed. Since it is difficult to collect reliable objective data such as income at a much later date, the choice of a prospective survey is usually considered the best means (Duncan and Kalton 1987).

In this paper we analyze data from the European Community Household Panel (ECHP), which is the panel with the longest duration currently available in Italy and provides information on the economic and reproductive histories of individuals. This paper represents a significant contribution to the literature on economic circumstances and fertility in Italy, both for its focus and for the data source used.

In line with Liefbroer and de Jong Gierveld (1996), we believe that fertility models which include only women's plans are mis-specified, and that asking women about their partners could cause bias estimates. For this reason we analyse data collected from both partners, and observe the interactions of their labour force status to see how they shape their fertility choices. Although most theoretical analyses emphasise that the 
fertility and labour force features of both partners are closely related (Oppenheimer 1994), the Italian experience of studies on couples has been occasional and not systematic (e.g., Sabbadini and Rosina 2007; Vignoli and Salvini 2008), because of the shortage of data on men. Hence, a further strength of this paper is the analysis at couple-level that provides insight into the interconnections between partners' working careers and childbearing choices.

The paper is structured as follows. In the next section we review the theoretical background on which the work is based. In section 3 we describe the main features of the Italian setting, with a focus on the main characteristics of the labour market and welfare system which could have some influence on childbearing. In section 4 we illustrate data, method, and research hypotheses. Results are discussed in section 5. Finally, section 6 presents our major findings and concluding remarks.

\section{Economic resources and childbearing: Theoretical background}

The role of the first child in fertility is particularly important in Italy. With the increasing postponement of the first birth, fecundity problems or union dissolution might occur, leading to an increase in childlessness and a reduction in the final fertility level (Livi Bacci 2001). Moreover, the first child has a specific value: most of childbearing's benefits, the realized wish of parenthood, the intrinsic value of children, the money support and security in old age, are provided by the first child. Every additional child contributes with a decreasing marginal utility to the couples' utility (Mazzuco and Ongaro 2006).

In developed countries like Italy, childbearing is planned rationally among other individual projects, e.g., educational or occupational, so that they interact reciprocally. Hence, among the determinants of childbearing, those of an economic nature are particularly important. On the one hand the availability of economic resources can induce couples to have children, while on the other hand couples can abandon the idea of having (more) children if they perceive that the children could negatively influence their own economic well-being.

The key assumption of this work is that individuals pool their economic resources and decide rationally to become parents when they can rely on a stable economic basis. A solid economic basis is given by enough income to support the household and a good degree of job stability. It is clear that individuals can evaluate these two economic requisites differently according to their personal values and orientations and the culture or the context in which they are embedded.

The New Home Economics (NHE) hypothesizes that partners manage their economic resources to maximize the utility function of goods and services purchased in 
the market (Becker 1960, 1965). This function has a budget constraint, the income from work, the amount of which varies according to the time spent working and on other activities (e.g., eating, sleeping, raising children, etc.). Thus, the crucial problem is how to allocate time optimally, so that the function is maximized. This decision is usually taken according to the comparative advantage theory, i.e., resources are allocated to various activities according to their comparative efficiencies (Becker 1991). Efficient households are those with the best division of time and human capital between partners, where the partner with the greatest advantage in the market specializes in the market and the partner with the greatest advantage in the household specializes in the home. The type of family considered in this approach is the classical male breadwinner family, where the husband participates in the labour force and the wife devotes her time to children and housework.

This gender specialization is particularly important when partners plan whether and when to have children. For Becker (1960), children are consumption goods with a given price which provide a given amount of utility. They can be supplied by the market and purchased by parents on the basis of their budget constraint, the income from work. Rational partners decide how and when to maximize their utility function: by consuming more goods or also having more children. Becker (1991) states that income is linked to childbearing according to three mechanisms: the income effect, the substitution effect, and the price of time effect.

The income effect is the positive effect of income on consumption: with increasing income, consumption of goods and of children increases. Such an effect is positive for male income, but it is not clear whether this is so for female income. For female income, the income effect interacts with the substitution effect, because the indirect cost of children (i.e., forgone incomes, interruptions in working careers, loss of experience and earnings, decrease of leisure time, lowering of the couple's living standards and, finally, health costs) increases with increasing female earnings. In classical male breadwinner couples, for working women the allocation of time between work and family is very difficult. This introduces the price of time effect and the issue of conciliation between work and family pressures (Becker 1965).

The price of time effect dominates the income effect among women, and the reverse holds for men. According to the supply-demand microeconomic theory, if household income increases, the demand for goods increases as well. The same should happen with children. If the rising income is that of the woman, the effect on the demand for children can be the opposite, because the relative cost of children is significantly affected by changes in the value of the woman's time, which is most of her total indirect cost of childbearing (Becker 1960, 1991).

Becker (1991) relates changes in fertility levels in modern societies to the improvement of women's socioeconomic status. For well-educated and working women 
both the time and opportunity costs of childbearing are very high. However, in countries with an egalitarian family system men participate in home duties, thus reducing the price of time effect for women (Liefbroer and Corijn 1999). Therefore, from this point of view the NHE's approach is not exhaustive, as the wider range of opportunities for women can influence men's role and change the gender relation within the couple (Oppenheimer 1994). Moreover, families dissolving traditional gender boundaries are more adaptive in actual societies (Mencarini 2007). On the contrary, in traditional settings men's contribution to household activities is scarce and the NHE's assumption holds.

The NHE approach to fertility does not explicitly include uncertainty, because it relies on the assumption of a perfect market. According to Mills and Blossfeld (2005), job instability is mostly due to the processes of liberalization and globalization that provoke market deregulation and increased flexibility, and enhance barriers between insiders and outsiders. The progressive liberalization of the labour market is weakening labour protection and making long term choices - such as investing in housing, forming a union, reaching parenthood - more difficult (Simò and Golsch 2000). The globalization process is currently introducing important constraints in individual lives, especially among the youngest. They have many difficulties in entering the job market, thus limiting their career development. This is particularly true for highly educated and skilled individuals, so that their future expectations and projects are stymied by the job market (Deriu 2008). It is hypothesized that parenthood is decided when a "relatively good" position in the labour market is reached (Mills and Blossfeld 2005). Simò and Golsch (2000) state that market uncertainty is a source of frustration for young people, so adding a constraint to their decisions. They perceive themselves as not being able to guarantee to their future children the standard of living they inherited from their parents.

This does not mean that only economic considerations are involved in the decision to have a child. Rather, achieving a minimal level of economic independence and security may be regarded as a "necessary but insufficient" condition to be fulfilled before childbearing (Bernardi and Nazio 2001:2). As a consequence, the youngest develop different rational strategies against uncertainty, e.g., remaining in education, postponing family formation, taking on multiple roles, or having children. In male breadwinner societies such strategies differ by gender. Men usually opt to postpone family formation and fatherhood, while women have two choices: low educated women, with scarce prospects of successful careers, tend to marry and have children to reduce uncertainty (Friedman, Hechter, and Kanazawa 1994), while highly skilled women postpone union formation and motherhood until they have achieved a stable position in the labour market (Mills and Blossfeld 2005). 
In uncertain contexts the male breadwinner model might not be perceived as a solution, and both partners might prefer to be employed and invest many years in accumulating human and economic capital to reduce future adversity. Consequently the rising female labour market participation can be seen as a strategy to cope with growing uncertainty (Oppenheimer 1994).

Research is not consolidated on whether and how fixed-term contracts affect the decision to get married and have children in Italy. However, some empirical studies (see e.g., Bernardi and Nazio 2001) show that economic insecurity makes the decision to have a first child less likely. In this work we expect that the massive introduction of short-term contracts did play a role in first birth choice at the end of last century and decreased the probability of couples becoming parents.

Whether and when individuals take childbearing decisions depend not only on their own preference structure, but also on the country-specific institutional context (Neyer 2006). Welfare mechanisms can reduce risks by decreasing family expenses or child-care time with financial support or childhood services, etc. Institutions can protect young people from uncertainty or unemployment with unemployment benefits, education grants, and housing subsidies. If welfare support is scarce the family is the only institution that helps young couples by transferring money, taking care of children, and capital saving. This is the subject of the next section.

\section{The economic situation of young people in Italy: An overview}

In Italy the labour market and the welfare system design make it difficult for young people to reach adulthood and the family is often the only support against their economic constraints. In spite of recent changes towards flexibility, the Italian labour market still remains highly regulated. Strict rules apply about hiring and firing workers and the types of employment arrangements. The Italian job market is characterized by long-term unemployment, low rates of mobility, and high insecurity. It presents a strong dichotomy between the insiders, i.e., the older cohorts who profit from strong employment protection, and the outsiders, i.e., the younger cohorts characterized by unemployment and unstable jobs (Pisati and Schizzerotto 2006).

Labour market instability began to spread at the end of the 1980s, due to a growing number of fixed-term contracts mostly restricted to young people, in particular highly skilled ones. The highly educated face unfavourable matches in the labour market and most of them remain under-exploited (Pisati and Schizzerotto 2006). In particular, in 1997 the "Treu package" introduced many kinds of fixed-time positions: co.co.co contracts for temporary collaborations, co.co.pro - contracts to collaborate on projects paid according to output, and often unpaid internships. These new employment forms 
are not adequately paid and are often irregular. Atypical workers are not properly protected with social contributions and against job loss. These new employment forms can be seen as part of organizational restructuring induced by the globalization process. On the one hand, they can be a way to off-set strict employment regulations and achieve more flexibility, and on the other hand, they indicate the increase of economic insecurity that pervades many aspects of life (Bernardi and Nazio 2001). Short-term jobs are not an efficient way to enter the labour market and do not rapidly turn into stable jobs. Furthermore, there has never been a national minimum income scheme and tax deductions are extremely low (Del Boca, Pasqua, and Pronzato 2005).

In addition, the Italian job market is highly sex-segregated and disparities are usually against women. Women's careers are more occasional than men's and women are paid less, and if they lose their jobs they are more likely than men to remain unemployed (Istat 2009b). Self-employed women and atypical workers are still poorly protected. Highly protective regulation of maternity leave has made female labour more costly than male labour, thus reducing the incentive for employers to hire women. Employers prefer men because they are less expensive (they do not receive maternity benefits) and are more likely to work overtime (Del Boca 2002).

Growing female labour market participation compels women to combine the roles of worker and mother, while institutions do not provide appropriate reconciliation instruments. Temporarily quitting their job should be a solution for women, but this implies loss of earnings, experience, and skills, besides the risk of not re-entering the market, especially in the private sector. Furthermore, as shown by Davies and Joshi (1994), forgone earnings are higher in countries like Italy where female labour market participation is lower. Therefore for a woman it may be optimal to delay motherhood until she has completed education, found a stable job, and her opportunity costs are the lowest.

Many studies show that the scarce availability of affordable child care services, the rigidity of the labour market, and the limited number of part-time jobs lead to a negative relation between female labour market participation and fertility in Italy at the individual level (see e.g., Del Boca, Pasqua, and Pronzato 2005; Rondinelli, Aassve, and Billari 2010). Such a result might also be the indicator of traditional gender roles within the couple. In more traditional settings women's time is entirely devoted to the family and men's time to the market. Welfare policies can promote an equal distribution of unpaid housework between men and women by levelling working perspectives and earnings in the market and duties in the family (Neyer 2006). Although women's preferences have started to change, a negative normative climate still persists in Italy and the change has not yet led to a general attitudinal shift. The traditional male breadwinner model was, and still is, strongly supported by relatively generous social insurance schemes and strict labour market regulations. However, its sustainability is 
becoming increasingly difficult as the number of dual-earner couples rises. In such a situation parents constitute for the youngest a defensive "shield" against the general uncertainties of their future. It is mainly the family and kinship networks that give support to young people: they are universal institutions which support individuals from birth to adulthood. Because of the lack of adequate social policies, young Italians delay the nest-leaving and other family formation phases. Furthermore, reaching adulthood does not necessarily imply the end of support from the family to young adults. In fact the period in which individuals rely on family has been extended to adulthood and even beyond (Santarelli and Cottone 2009). This certainly has an important role in childbearing decisions.

What has been described so far shows that in Italy little is done by institutions to support fertility decisions. If combining motherhood and work was made easier by the welfare system and the labour market, a high female income could foster fertility. Whether and how couples' economic resources are associated with childbearing is highly dependent on women's presence in the labour market and on the extent to which family policies, the labour market, and culture alleviate the burden of childrearing (Neyer 2006).

\section{Data, methods, and research hypotheses}

In this work we think in terms of spouses' life-course strategies that are continuously being updated, as partners are faced with a dynamic system of choices, restrictions, and chance outcomes. Such strategies produce interactions between partners' educational and job careers on the one hand, and their family histories on the other. For this reason we use a couple approach and analyse a sample of childless couples drawn from the ECHP.

The ECHP is a prospective survey with information on labour, income, and fertility histories. The panel coves eight years (1994 to 2001), a sufficiently long period to study reproductive events. The ECHP provides data on several household and individual features and it allows for the reconstruction of precise educational attainment, as well as employment and marital and reproductive careers. Its multidimensional and multipurpose nature makes possible the study of changes in the socioeconomic status, life events, behaviours, and values of individuals and households, and of how such changes interact.

In this work we restrict the analyses to married couples. In fact the onset of the couple's risk of having a first child is usually the start of the union, but this information 
is not available for cohabiting couples in the ECHP ${ }^{4}$. However, since unmarried parenthood is still rare in Italy, we capture the large majority of births. We exclude couples who live with children born from previous unions or with other adults (e.g. spouses' parents), because they could provide economic support to households and invalidate the key assumption of section 2 . The process time is the duration of the marriage. Couples are followed from the second wave of the survey ${ }^{5}$ (1995) (spell data are left-truncated) up to the first conception ${ }^{6}$ if it happens, or the last interview if the event does not happen. Couples are censored if the woman reaches 45 years (it is very unlikely for women over 45 to become pregnant for the first time), if the marriage dissolves, if someone enters the family (e.g. if the spouses' parents move in), or at last interview; whichever comes first.

We take into account that analyzing married couples makes the sample a selected group with respect to childbearing choices. In fact, those who are economically unstable may cohabit, delay marriage, or choose not to marry at all (Mills and Blossfeld 2005). People who marry usually have a higher family orientation than single people or individuals in consensual unions, and therefore a higher propensity to have children (Baizan, Aassve and Billari 2003). Among dual earner couples the woman's labour force status and income can be linked to marriage dissolution before parenthood, so there could be endogeneity between processes, which can bias the results. In our models we do not control for endogeneity, so we do not indicate a direction of causality which runs from the covariates to fertility, but just identify patterns of association between couples' economic resources and the risk of first conception. We take into account all these issues in the comments on the results.

Our sample comprises 726 couples. 354 of them, $48.8 \%$ of the total, had a first child during the seven-year panel (see Appendix Table A1 for some statistics). Since they are followed for seven waves, this is not an indication of final fertility levels, but only of transitions occurred during the observation window.

The analysis is performed with a Cox model, i.e., the baseline hazard is given no particular parametrization and is left unspecified (Blossfeld and Rohwer 1995). All covariates included in the model are time-varying in order to evaluate the effect of occupational and economic changes over time. All variables are surveyed annually, so we do not know whether and how their value changed during each year. We assume that covariates are fixed until the next interview.

\footnotetext{
${ }^{4}$ In all waves of ECHP cohabiting couples are always less than $3 \%$.

${ }^{5}$ In the first wave of ECHP (1994) data on the type of contract are not collected.

${ }^{6}$ As in many empirical studies (e.g. Baizan 2007; Kreyenfeld 2004), the event is nine months before birth to: i) study the impact of economic resources on the decision to conceive the first child and ii) to avoid reverse causation.
} 
Concerning individual characteristics, we first consider the woman's age, because the rate of entry into motherhood shows a strong age-dependent pattern. We expect that it is negatively associated with the rate of the first child, because childbearing mainly depends on woman's fecundity, which diminishes with age. We include the man's age as well and expect that it does not influence the risk of a first child, because childbearing is more related to the woman's life course than the man's.

Among economic resources we firstly take into account the spouses' education, because it is a kind of human capital (Becker 1964). The NHE argues that a high education results in higher opportunity costs of childbearing, especially for mothers, because they get lower rewards for their schooling investment. This implies that fertility decreases quite sharply with increasing education (Becker 1960). Hence, we expect that couples with highly educated spouses have a lower first child risk than others.

As far as the couple's working status is concerned, we include the couple's employment arrangement as either single or dual earner. In 1995 about $46 \%$ of couples in our sample are dual earner, while the remainder are mostly single earners where the woman is not working (see Table 1). Furthermore, across waves not less than $80 \%$ of women in one-income couples are housewives and therefore economically inactive. We argue that their choice not to work could largely depend on their high family orientation. We expect that male breadwinner couples have a higher propensity for children than dual earners couples. Women who are not working do not face conciliation problems and do not bear indirect costs. In dual earner couples opportunity costs could be so high that women prefer to postpone the first conception (Livi Bacci 2001). In a context like Italy, where the institutions impose many constraints on the simultaneous fulfilment of the roles of mother and worker, the role of opportunity costs for working women could be crucial to couples' fertility choices.

The first key covariate of our model is income from work. Income is considered separately for men and women to evaluate whether different mechanisms by gender are at work in the income-fertility link, as discussed in section 2. It is the single annual income from work, declared net by respondents, and refers to the year prior to the survey. This could be an advantage for our study, since it avoids the reverse effect of fertility on labour market participation, especially among women. The man's income from work is divided into three percentile groups $(0 \%-33 \%, 34 \%-66 \%, 67 \%-100 \%)$, which we classify as low, medium, and high income. We classify women according to their labour market status and income level: housewife, unemployed, working womenlow income, working women-high income. This classification allows us to distinguish women by income level and, for women without income, whether they are housewives or unemployed, since they could have very different fertility patterns. In general, the results of past empirical studies have been ambivalent. Income can affect the timing of the first child in different ways. According to the NHE, male income is positively 
linked with fertility, due to a direct income effect, and we expect a similar finding. As concerns women's income, we argue that, among working women, high earnings imply a long time spent in education and in search of a stable job. Thus, a long time is taken to get enough money to form a new family and enter motherhood. We argue that high income women bear high opportunity costs and postpone the first child until costs are the lowest. Due to the constraints imposed by the labour market and the lack of institutional support, we expect that if woman's income increases, the first birth risk reduces, so that the substitution effect prevails.

Among financial resources we also consider transfers from the state and from private sources. We define social transfers as the sum of unemployment and disability benefits, and education, family, and housing related allowances. There are a few studies in the literature on how social transfers can act on fertility choices: see, e.g., Giraldo, Mazzuco and Michielin (2005), Hoem (2000) and Del Boca, Pasqua and Pronzato (2005). The relation can be dual: it could be assumed that spouses receiving low social support are in bad economic conditions or have health problems and postpone the first birth. Furthermore, couples can be induced not to have children at all, because of the low social support. In fact, according to De Santis and Livi Bacci (2001), such couples prefer to save money against possible future worsening of their living standards, and this could conflict with the decision to have a child. Since in Italy social benefits are very rare and, where present, scarce, they might not have any impact at all.

We define private transfers as any financial support that the respondent received from relatives, friends, or other persons outside the household. To our knowledge no empirical studies have been carried out on the impact of private transfers on fertility in Italy, mainly because such information is not available in demographic surveys. In this study we have the opportunity to evaluate the role of such economic resources, since the ECHP provides data on private transfers received by the couple. We assume that they can be associated with social transfers and act in a similar way.

While information on income is very detailed in the ECHP, only one question is asked about the type of contract (permanent or temporary), because the survey was not specifically designed to investigate employment instability. Consequently in this work the impact of unstable jobs is tested with a variable that classifies dependable work as permanent and fixed-termed. As an indicator of economic insecurity we have built a variable with all the possible combinations of working arrangements according to the type of contract (see Table 1). In this work we follow Istat's guidelines (2009b) and define unstable or uncertain jobs as fixed-term subordinate working contracts and fulltime or part-time apprenticeships, as well as atypical or "non standard" contracts, scholarships, research and doctorate grants, job on call, job sharing, etc. In the definition of such a variable we consider self-employed individuals as working 
permanently, because in Italy at the time of the survey they correspond to stable positions in the market (Bernardi and Nazio 2001).

Table 1 shows that in 1995 most couples in our sample were male breadwinner with the man permanently employed (43.7\%), while $40.58 \%$ were dual earner couples with both spouses working permanently. Other couples do not have standard working arrangements. We interpret these figures, in line with Billari and Ongaro (1998), as the fact that in Italy people marry after at least one partner, usually the man, has found a stable job. We argue that one-income couples with the man permanently employed encounter the highest first child rates, because they have a stable income and nonworking women do not have indirect costs. We expect that couples with both spouses permanently employed have the next highest risk, while couples where one or both partners are unemployed or economically unstable have the lowest first birth rates. In fact, individuals with fixed-term contracts are forced to continuously redefine their choices and to postpone parenthood until they are stable. They are less protected regarding the access to conciliation measures, such as parental leave. Again, having a child may interfere with the chances of obtaining more stable employment, and, more generally, with getting established on a career track.

Then we include the area of residence: North, Centre, South, and Islands. This is a time-varying variable, so that we can take into account residential changes over time. The area of residence is the only variable possibly expressing contextual characteristics: differences in the rate of first conception by place of residence could express the influence of macro unobserved factors such as labour market and cultural and institutional settings. In fact many empirical studies show that in Italy local socioeconomic, institutional, and cultural backgrounds are prominent elements influencing childbearing (see, e.g., Dalla Zuanna and Righi 1999). The North and Centre record higher educational attainment and female labour market participation than the South, as well as a more flexible labour market (more part time job availability) and modern family behaviours (living alone before marriage, a large number of consensual unions). They also register a later transition to marriage than the South (Billari and Ongaro 1998). As a consequence, we expect that couples in the North and Centre have a lower first child risk than Southern couples. 
Table 1: Married couples by partners' employment arrangement and type of contract in $1995(\%)$

\begin{tabular}{lccc}
\hline & Woman not working & $\begin{array}{c}\text { Woman working: } \\
\text { permanent or } \\
\text { self-employed }\end{array}$ & $\begin{array}{c}\text { Woman working: } \\
\text { temporary or } \\
\text { without contract }\end{array}$ \\
\hline $\begin{array}{l}\text { Man not working } \\
\begin{array}{l}\text { Man working: permanent or } \\
\text { self-employed }\end{array}\end{array}$ & 4.46 & 0.64 & 1.78 \\
$\begin{array}{l}\text { Man working: temporary or } \\
\text { without contract }\end{array}$ & 43.70 & 40.58 & 3.57 \\
\hline
\end{tabular}

Source: own elaborations on ECHP data.

\section{Results}

In this section we present the results of the Cox model on the link between a couple's economic resources and instability and entry into parenthood. They are shown in Table 2, where three models are presented (A, B, and C).

In model A we include the following covariates: woman's age and educational attainment, couples' employment arrangement, and area of residence. The effect of female age takes a bell-shaped form, but parameter estimates are not always significant (except in model B). Also the man's age is not significantly linked with first child rate and we decide not to include this covariate in the final model.

Results for education show that women's school level is not significantly associated with the transition to first birth during the studied period. This result could be surprising compared to the majority of empirical findings. According to many authors (see, e.g., Bratti (2003) and Ongaro and Salvini (2003)) education is negatively associated with first child risks and this usually reflects the fertility postponement of the better educated women. We argue that our result can be due to the fact that we focus on married couples. Very educated women marry later, but when they marry they probably have the same birth rate as less educated women. Male education is also not significant and we do not include it in the final model A.

Results on the couple's employment arrangement clearly show that single earner couples have a $33 \%$ higher first birth risk than dual earner couples. Such a result is consistent with other empirical studies showing that in Italy couples with non-working women have higher first birth risks, probably because they anticipate the first child (Baizan 2007; Vignoli and Salvini 2008). The majority of Italian married couples want to have children (Castagnaro and Di Priamo 2003), so the most important difference 
among them is on the timing of the first birth. Childbearing is very costly for employed mothers, so that after marriage they postpone their first child to limit indirect costs.

Estimates on the area of residence are not significant, indicating that residing in the North, Centre, or South does not distinguish couples in their transition to first birth. Hence, there is no evidence that institutional or cultural effects are responsible for the postponement of maternity at the turn of the twentieth century. We interpret this finding in line with Mazzuco and Ongaro (2006), i.e., the first childbirth is a "special" choice, highly desired by married couples, independently of economic, cultural, and institutional conditions, notwithstanding their large differences across Italy.

Table 2: Relative risks of first child of childless married couples in Italy (month of conception), 1995-2001

\begin{tabular}{|c|c|c|c|c|}
\hline & & Model A & Model B & Model C \\
\hline \multirow{5}{*}{ Woman's age } & up to 24 (ref.) & 1 & 1 & 1 \\
\hline & $25-29$ & 1.20 & 1.17 & 1.31 \\
\hline & $30-34$ & 1.15 & 1.15 & 1.30 \\
\hline & $35-39$ & 0.61 & $0.56^{*}$ & 0.63 \\
\hline & $40-45$ & 0.48 & 0.44 & 0.48 \\
\hline \multirow{3}{*}{ Woman's educational level } & low (ref.) & 1 & & \\
\hline & medium & 0.87 & & \\
\hline & high & 0.94 & & \\
\hline \multirow{2}{*}{ Couple's employment model } & dual earner (ref.) & 1 & & \\
\hline & single earner & $1.33^{* *}$ & & \\
\hline \multirow{4}{*}{ Couple's working stability } & both permanently employed (ref.) & & & 1 \\
\hline & only man permanently employed & & & 0.82 \\
\hline & not standard working & & & \\
\hline & arrangements & & & 0.94 \\
\hline \multirow{3}{*}{ Man's income from work } & low level (ref.) & & 1 & \\
\hline & medium level & & 1.06 & \\
\hline & high level & & 1.06 & \\
\hline \multirow{4}{*}{$\begin{array}{l}\text { Woman's labour market } \\
\text { status }\end{array}$} & housewife (ref.) & & 1 & \\
\hline & unemployed & & 1.21 & \\
\hline & low income & & $0.67^{* \star *}$ & \\
\hline & high income & & $0.70^{*}$ & \\
\hline
\end{tabular}


Table 2: (Continued)

\begin{tabular}{|c|c|c|c|c|}
\hline & & Model A & Model B & Model C \\
\hline \multirow{2}{*}{$\begin{array}{l}\text { Couple's income from } \\
\text { social transfers }\end{array}$} & No (ref.) & & 1 & \\
\hline & Yes & & 1.22 & \\
\hline \multirow{3}{*}{$\begin{array}{l}\text { Couple's income from. } \\
\text { private transfers }\end{array}$} & No (ref.) & & 1 & \\
\hline & Yes & & 0.89 & \\
\hline & North (ref.) & 1 & 1 & 1 \\
\hline \multirow[t]{2}{*}{ Area of residence } & Centre & 1.06 & 1.05 & 1.09 \\
\hline & South & 1.18 & 1.21 & 1.20 \\
\hline Log-L & & -1636.987 & -1764.159 & -1417.257 \\
\hline
\end{tabular}

Source: own elaboration on ECHP data.

Note: ${ }^{*}=p<0.10,{ }^{* *}=p<0.05,{ }^{* * *}=<0.01$.

Model B includes covariates on the woman's age, male income, female labour market status, other sources of income, and area of residence. Firstly, we found the unexpected result that the man's income is not significantly linked with fatherhood. Contrary to our hypothesis, the choice to have the first child appears to be irrespective of the male income level.

Secondly, we find that women who have a labour income have much lower first birth rates than non-working women. Among working women a high income makes the first child risk slightly higher than a low income. We interpret this result in line with the opportunity costs theory. Employed wives postpone motherhood, because an exit from the market could damage their skills and future labour market prospects. In fact, higher depreciation of human capital during their absence for maternity corresponds to lower wages in the future. This aspect is very important in Italy, where women's participation is low and childbearing costs are high, unless specific measures are taken to improve the compatibility of employment and childbearing (Davies and Joshi 1994).

Concerning other types of income, our estimates reveal that incomes from social and private transfers are not significantly associated with first birth propensity. This result supports our hypotheses and it is explained by the low amount of such benefits.

Finally, the area of residence is not significantly linked with parenthood.

In model $\mathrm{C}$ we test couples' job stability as the main covariate. A surprising result is that the level of job stability is not significantly associated with parenthood during the years under study, and we argue that this comes from the fact that a large majority of the selected couples are permanently employed. We interpret this as one of the consequence of analyzing married couples: due to the difficulties of entering the market, young people in Italy marry only after at least one partner has found a stable job to support the newly formed family (Billari and Ongaro 1998). This is usually the 
case for men: the stability of future income streams is a crucial factor in enabling them to start a family.

\section{Conclusions}

The weak connection between the educational system and the labour market, and the rigidity of the job market and the inefficiency of the welfare state, make transition to adulthood increasingly difficult for young Italians. Such elements have made, and still are making, changes in economic and social life faster and less predictable. Job and income insecurity lead young people to choices other than union formation and parenthood, because they are not compatible with the instability of their working status. A sense of insecurity about economic resources has been spreading since the end of the 1980s, especially among the youngest, due to labour reforms that introduced many kinds of temporary jobs. This certainly has consequences for individual family and fertility plans.

In this work we analyzed whether and how economic resources, in particular income and job stability, are linked to first parenthood in Italy at the end of the twentieth century. Such studies are quite infrequent, mostly due to the shortage in demographic surveys of longitudinal data on income and type of contract. Using data from the ECHP, we studied the transition to parenthood of a sample of married couples in association with covariates on education, income, and various job characteristics, during the period 1995-2001. This study constitutes an important contribution to the scarce literature on the link between economic circumstances and fertility in Italy. We employed a couple approach to take into account the interconnections between spouses' labour force status and economic resources.

Our findings show that the employment arrangement significantly differentiates married couples in their transition to parenthood. In particular, male breadwinner couples have their first child earlier than dual earner couples. Very interesting results are obtained on the link between income and first child risk: firstly, male earnings are not significantly associated with first parenthood; secondly, women who have an income have much lower first births rate than non-working women. Furthermore, among working women those with higher earnings encounter a slightly higher first birth risk than low income women. Our analyses show that other kinds of income (transfers from the state and from private sources) do not matter for first birth decisions either. We interpret these results in the light of the specific features of the cultural and institutional Italian context. We argue that at the end of the last century the persistence

of the male breadwinner model makes the stability of the man's employment position a necessary requisite for having a first child, regardless of the income level. For women 
the main difference in the transition to motherhood seems to be between working and non-working women. When looking at the role of employment careers from a couplelevel interaction, the woman's position in the labour market plays a key role in the transition to parenthood. Due to the persistence of traditional gender roles within the family and high constraints from the labour market, working women's childbearing decisions are conditioned by many constraints. A great degree of incompatibility between family and work still persists and little has been done by institutions in recent years to make the conciliation easier.

Another interesting result of our study is that the degree of job stability is not linked to the entry into parenthood, and we interpret this as a consequence of analyzing married couples. This result does not imply that job stability does not matter in the transition to parenthood. We argue that it indirectly influences parenthood by delaying union formation: results by Bernardi and Nazio (2001) and Billari and Rosina (2004) show that job precariousness has a negative influence on union formation and marriage both for women and for men. Hence, income and job stability should also be analyzed in connection with union formation: comparing the results of the transition to marriage or cohabitation and to parenthood may show in which phase of the transition to adulthood economic instability is effective, and how.

This work adds new insights to the research on economic resources and fertility in Italy, which so far has been limited due to a lack of suitable data. Firstly, the ECHP provides rich employment data and allows the inclusion in the analyses of different kinds of income, which is an important element in childbearing decisions. Secondly, the ECHP allows the adoption of a couple approach in order to shed light on the interrelations between the economic prospects and careers of both spouses. In particular, it allows the examination of how partners' characteristics can interact to diminish or neutralize economic uncertainties. We recommend that features of both partners are included when planning social surveys, so that how they interact reciprocally to cancel out economic constraints can be explored.

This study certainly has some limitations. One of these is that it only focuses on married couples and this makes our sample a selected group with respect to fertility decisions. A further limitation is the small sample size. As pointed out in section 4, these shortcomings are due to the design of ECHP, which, however, is the only survey currently available in Italy to study economic resources and parenthood at the end of the twentieth century from a couple perspective. 


\section{Acknowledgments}

Many thanks are due to Dr. Lucia Coppola for her very kind and constant help in various phases of data processing and to Dr. Francesca Utili for her advices on a first draft. I thank the Editors of Demographic Research and the anonymous reviewers for their useful comments and suggestions. An earlier version of this paper has benefited from comments received by participants at the Workshop "Economic Uncertainty and Family Dynamics" (Berlin, July 3-4, 2009), who are gratefully acknowledged. 


\section{References}

Baizan, P. (2007). The impact of labour market status on second and higher-order births. In: Esping-Andersen, G. (ed.). Family formation and family dilemmas in contemporary Europe. Madrid: Fundación BBVA: 93-127.

Baizan, P., Aassve, A., and Billari, F.C. (2003). Cohabitation, marriage and first birth: The interrelationship of family formation events in Spain. European Journal of Population 19(2): 147-169. doi:10.1023/A:1023343001627.

Becker, G.S. (1960). An economic analysis of fertility. In: N.B. of Economic Research (ed.). Demographic and economic change in developed countries. Princeton University Press: 209-231.

Becker, G.S. (1964). Human capital. New York: Columbia University Press.

Becker, G.S. (1965). A theory of allocation of time. Economic Journal 75(299): 493517. doi: $10.2307 / 2228949$.

Becker, G.S. (1991). A treatise on family. Cambridge: Harvard University Press.

Bernardi, F. and Nazio, T. (2001). Globalization and the transition to adulthood in Italy. In: Blossfeld, H.-P., Klijzing, E., and Mills, M. (eds.). Globalization, uncertainty and youth in society. Chapter 14. London and New York: Globalife: 349-374.

Billari, F.C. (2005). Europe and its fertility: From low to lowest-low. National Institute Economic Review 194(1): 56-73. doi:10.1177/0027950105061496.

Billari, F.C. and Ongaro, F. (1998). The transition to adulthood in Italy. Evidence from cross-sectional surveys. Espace, Populations, Societes 2: 165-179.

Billari, F.C. and Rosina, A. (2004). Italian latest-late transition to adulthood: An exploration of its consequences on fertility. Genus LX(1): 71-88.

Blossfeld, H.-P. and Rohwer, G. (1995). Techniques of event history modelling. New approaches to causal analysis. Mahwah, New Jersey: Lawrence Erlbaum Associates.

Bratti, M. (2003). Labour force participation and marital fertility of Italian women: The role of education. Journal of Population Economics 16(3): 525-554. doi:10.1007/s00148-003-0142-5.

Castagnaro, C. and Di Priamo, C. (2003). Le neo-mamme "non lavoratrici" e le forze di lavoro potenziali. In: Istat, Cnel (eds.) Maternità e partecipazione delle donne al mercato del lavoro tra vincoli e strategie di conciliazione. Rome. 
Dalla Zuanna, G. and Righi, A. (1999). Nascere nelle 100 Italie. Comportamenti coniugali e riproduttivi nelle province italiane negli anni 80 e 90. Rome: Istat. (Argomenti 18).

Davies, H. and Joshi, H. (1994). The foregone earnings of Europe's mothers. In: EkertJaffè, O. (ed.). Standard of living and families: Observation and analysis. Paris: John Libbey Eurotext: 101-134.

De Santis, G. and Livi Bacci, M. (2001). Reflection on the economics of fertility decline in Europe. Paper presented at the EURESCO Conference "The 2nd demographic transition in Europe", Bad Herrenalb, Germany, June 23-28, 2001.

Del Boca, D. (2002). The effect of child care and part time opportunities on participation and fertility decisions in Italy. Journal of Population Economics 15(3): 549-573. doi:10.1007/s001480100089.

Del Boca, D., Pasqua, S., and Pronzato, C. (2005). Fertility and employment in Italy, France, and the UK. Labour: Review of Labour Economics and Industrial Relations 19: 51-77.

Deriu, F. (ed.) (2008). Orizzonti difficili. Instabilità lavorativa e scelte familiari a Roma. Rome: Carocci.

Duncan, G. and Kalton, G. (1987). Issues of design and analysis of surveys across time. International Statistical Review 55(1): 97-117. doi:10.2307/1403273.

Friedman, D., Hechter, M., and Kanazawa, S. (1994). A theory of the value of children. Demography 31(3): 375-401. doi:10.2307/2061749.

Giraldo, A., Mazzuco, S., and Michielin, F. (2004). Il ruolo del reddito nelle decisioni di fecondità. In: Proceedings of the Conference "La bassa fecondità tra costrizioni economiche e cambio dei valori". Rome: Accademia nazionale dei Lincei: 223-241.

Giraldo, A., Mazzuco, S., and Michielin, F. (2005). Compatibility of children and work preferences: Two European cases. Padua: University of Padua, Department of Statistical Sciences, working paper. (WP-2005-8).

Hoem, B. (2000). Entry into motherhood in Sweden: The influence of economic factors on the rise and fall in fertility, 1986-1997. Demographic Research 2(4). doi:10.4054/DemRes.2000.2.4.

Istat (2000). Rapporto annuale. La situazione del paese nel 2000. 
Istat (2009a). Sistema di Indicatori Territoriali. [electronic resource]. Rome. http://sitis.istat.it/sitis/html/index.htm.

Istat (2009b). Le difficoltà nella transizione dei giovani allo stato adulto e le criticità nei percorsi di vita femminili. [electronic resource]. Rome. http://www.istat.it/salastampa/comunicati/non_calendario/20091228_00/.

Kreyenfeld, M. (2004). Fertility decisions in the FRG and GDR: An analysis with data from the German fertility and family survey. Demographic Research SC3 (11): 273-318. doi:10.4054/DemRes.2004.S3.11.

Liefbroer, A. and Corijn, M. (1999). Who, what, where and when? Specifying the impact of educational attainment and labour force participation on family formation. European Journal of Population 15(1): 45-75. doi:10.1023/A:1006137104191.

Liefbroer, A. and de Jong Gierveld, J. (1996). It takes two to tango, doesn't it? The influence of couple characteristics on the timing of the birth of the first child. Journal of Marriage and Family 58(1): 117-126. doi:10.2307/353381.

Livi Bacci, M. (2001). Too few children and too much family. Daedalus 130(3): 139155.

Mazzuco, S. and Ongaro, F. (2006). Costi e benefici dei figli. In: Ongaro, F. (ed.). Scelte riproduttive fra costi, valori, opportunità. Chapter 4. Milano: Franco Angeli: 83-108.

Mencarini, L. (2007). Sistema di genere asimmetrico e bassa fecondità. In: Gruppo di Coordinamento per la Demografia (ed.). Rapporto sulla popolazione. L'Italia all'inizio del XXI secolo. Chapter 3.2. Bologna: Il Mulino: 83-85.

Mills, M. and Blossfeld, H.-P. (2005). Globalization, uncertainty and the early life course. A theoretical framework. In: Blossfeld, H.-P., Klijzing, E., Mills, M., and Kurz, K. (eds.). Globalization, uncertainty and youth in Society. London and New York: Globalife: 1-24.

Neyer, G. (2006). Family policies and fertility in Europe. Fertility policies at the intersection of gender policies, employment policies and care policies. Rostock: Max Planck Institute for Demographic Research, MPIDR working paper. (WP2006-10).

OECD (2002). OECD Employment Outlook.

OECD (2004a). Education at a glance. 
OECD (2004b). OECD Employment Outlook.

Ongaro, F. and Salvini, S. (2003). Variazioni lavorative e passaggi di parità. In: Breschi, M. and Bacci, M.L. (eds.). La bassa fecondità fra costrizioni economiche e cambio di valori. Presentazioni delle indagini e risultati. Udine: Forum.

Oppenheimer, V. (1994). Women's rising employment and the future of the family in industrial societies. Population and Development Review 20(2): 293-342. doi: $10.2307 / 2137521$.

Pisati, M. and Schizzerotto, A. (2006). Mid-career women in contemporary Italy: Economic and institutional changes. In: Blossfeld, H.-P. and Hofmeister, H. (eds.). Globalization, uncertainty and women's careers. Cheltenham, UK and Northampton, USA: Edward Elgar: 352-375.

Rondinelli, C., Aassve, A., and Billari, F.C. (2010). Women's wages and childbearing decisions: Evidence from Italy. Demographic Research 22(19): 549-578. doi:10.4054/DemRes.2010.22.19.

Sabbadini, L. and Rosina, A. (eds.) (2007). Diventare padri in Italia. Fecondità e figli secondo un approccio di genere. Rome: Istat. (Argomenti 31).

Salvini, S. and Ferro, I. (2007). Young workers and flexibility of the labour market: What family strategies? Florence: University of Florence, Department of Statistics, working paper. (WP-2007-13).

Salvini, S., Pasqual, S., and Vignoli, D. (2009). Strategie lavorative e intenzioni riproduttive di uomini e donne in coppia: uno sguardo alla situazione italiana. Florence: University of Florence, Department of Statistics, working paper. (WP2009-08).

Santarelli, E. (2010). Economic resources and marital childbearing in Italy between 1994 and 2004. In: Proceedings of the " $45^{\text {th }}$ Scientific Meeting of the Italian Statistical Society”. (Padua, June 16-18).

Santarelli, E. and Cottone, F. (2009). Leaving home, family support and intergenerational ties in Italy: Some regional differences. Demographic Research 21(1): 1-22. doi:10.4054/DemRes.2009.21.1.

Simò, C. and Golsch, K. (2000). The transition to motherhood under the globalization process. Bielefeld: University of Bielefeld, Globalife working paper (WP-200004). 
Santarelli: Economic resources and the first child in Italy: A focus on income and job stability

Vignoli, D. and Salvini, S. (2008). Couples' careers, self selection, and fertility in Italy. In: Proceedings of the " $44^{\text {th }}$ Scientific Meeting of the Italian Statistical Society". (Arcavacata di Rende, June 25-27). 


\section{Appendix}

Table A1: Progression to first birth in Italy: Exposures and events in the study population

\begin{tabular}{|c|c|c|c|c|c|}
\hline \multicolumn{6}{|c|}{$\begin{array}{ll}\text { Number of couples: } & 726 \\
& \text { Number of first births: } 354 \\
\end{array}$} \\
\hline \multirow[b]{2}{*}{ Covariates } & & \multicolumn{2}{|c|}{$\begin{array}{l}\text { Couples' months } \\
\text { observed childless }\end{array}$} & \multicolumn{2}{|c|}{ First births } \\
\hline & & Abs. values & $\%$ & Abs. values & $\%$ \\
\hline \multirow{5}{*}{ Woman's age } & up to 24 & 2,013 & 11.2 & 56 & 15.8 \\
\hline & $25-29$ & 7,824 & 43.3 & 168 & 47.5 \\
\hline & $30-34$ & 5,645 & 31.3 & 110 & 31.1 \\
\hline & $35-39$ & 2,492 & 13.8 & 16 & 4.5 \\
\hline & $40-45$ & 77 & 0.4 & 4 & 1.1 \\
\hline \multirow{3}{*}{$\begin{array}{l}\text { Woman's } \\
\text { educational level }\end{array}$} & low & 2,115 & 11.7 & 44 & 12.4 \\
\hline & medium & 10,017 & 55.5 & 183 & 51.7 \\
\hline & high & 5,919 & 32.8 & 127 & 35.9 \\
\hline Couple's & dual earner & 12,943 & 71,7 & 224 & 63.3 \\
\hline employment model & single earner & 5,108 & 28,3 & 130 & 36.7 \\
\hline \multirow{3}{*}{$\begin{array}{l}\text { Couple's } \\
\text { working stability }\end{array}$} & both permanently employed & 4,399 & 24.4 & 98 & 27.8 \\
\hline & only man permanently employed & 10,852 & 60.1 & 191 & 54.0 \\
\hline & not standard working arrangements & 2,800 & 15.5 & 65 & 18.2 \\
\hline \multirow{3}{*}{$\begin{array}{l}\text { Man's } \\
\text { income from work }\end{array}$} & low level & 6,630 & 36.8 & 142 & 40.1 \\
\hline & medium level & 6,614 & 36.6 & 125 & 35.3 \\
\hline & high level & 4,807 & 26.6 & 87 & 24.6 \\
\hline & housewife & 3,799 & 21.0 & 95 & 26.8 \\
\hline Woman's & unemployed & 1,958 & 10.8 & 45 & 12.7 \\
\hline \multirow[t]{2}{*}{ labour market status } & low income & 6,296 & 35.0 & 117 & 33.1 \\
\hline & high income & 5,998 & 33.2 & 97 & 27.4 \\
\hline Couple's income & no & 16,344 & 90.5 & 321 & 90.7 \\
\hline from social transfers & yes & 1,707 & 9.5 & 33 & 9.3 \\
\hline Couple's income & no & 16,817 & 93.2 & 331 & 93.5 \\
\hline \multirow{2}{*}{ from private transfers } & yes & 1,234 & 6.8 & 23 & 6.5 \\
\hline & North & 8,555 & 47.4 & 140 & 39.6 \\
\hline \multirow[t]{2}{*}{ Area of residence } & Centre & 2,733 & 15.1 & 51 & 14.4 \\
\hline & South & 6,763 & 37.5 & 163 & 46.0 \\
\hline
\end{tabular}

Source: own elaboration on ECHP data. 
Santarelli: Economic resources and the first child in Italy: A focus on income and job stability 